\title{
EFEITOS DO HERBICIDA GLIFOSATO E DA APLICAÇÃO FOLIAR DE MICRONUTRIENTES EM SOJA TRANSGÊNICA
}

\author{
EFFECTS OF GLYPHOSATE AND FOLIAR APPLICATION OF MICRONUTRIENTS \\ IN TRANSGENIC SOYBEAN
}

\author{
Aldo MEROTTO JR ${ }^{1}$; Juliano WAGNER ${ }^{2}$; Cátia MENEGUZZI ${ }^{3}$ \\ 1. Professor, Doutor, Universidade Federal do Rio Grande do Sul - UFRS, Porto Alegre, RS, Brasil, merotto@ufrgs.br; 2. Engenheiro \\ Agrônomo, Mestre. Cooperativa Central Gaúcha Ltda, Cruz Alta, RS, Brasil; 3. Engenheira Agrônoma, UFRGS Porto Alegre, RS, \\ Brasil.
}

\begin{abstract}
RESUMO: A característica quelante do glifosato pode ocasionar a imobilização de nutrientes como Fe e Mn em soja transgênica resistente a este herbicida. No entanto, a intensidade deste efeito e o resultado de formas de mitigação deste processo são pouco conhecidos. O objetivo deste estudo foi identificar os efeitos do herbicida glifosato em interação com a fertilização foliar em cultivares de soja transgênica que apresentam a ocorrência de sintomatologia de amarelecimento relacionada à fitointoxicação deste herbicida. O primeiro experimento foi utilizado para a identificação de cultivares que mais apresentavam o sintoma de amarelecimento como consequência da aplicação do herbicida glifosato. $\mathrm{O}$ segundo experimento foi realizado a campo, onde os tratamentos constaram das cultivares CD 206RR e Fundacep 59RR, do herbicida glifosato aplicado nas doses de 0,900 e $1440 \mathrm{~g} \mathrm{ha}^{-1}$ e. a., e da presença ou ausência de adubação foliar na dose de 1,5 $\mathrm{L} \mathrm{ha}^{-1}$. O efeito do herbicida glifosato e da utilização de adubo foliar não alterou o teor dos micronutrientes Fe e Mn e os parâmetros de fluorescência da clorofila nas cultivares de soja CD 206RR e Fundacep 59RR. O herbicida ghifosate diminui o rendimento de grãos da cultivar Fundacep 59 RR. A fertilização foliar não foi eficiente como forma de aumentar o rendimento de grãos de soja.
\end{abstract}

PALAVRAS-CHAVE: Amarelecimento. Ferro. Fluorescência da clorofila. Manganês. Soja Roundup Ready.

\section{INTRODUÇÃO}

O desenvolvimento de plantas transgênicas ocorreu a partir da necessidade de facilitar o controle de plantas daninhas e insetos, diminuir o uso de pesticidas, e da possibilidade de obtenção de plantas menos suscetíveis a condições de estresses (MONQUEIRO, 2005). Neste contexto, as plantas transgênicas são uma alternativa importante para a agricultura, pois podem promover o aumento da produção (ISAAA, 2012) e a diminuição do uso de produtos fitossanitários. A utilização de cultivo de transgênicos tem aumentado na última década principalmente nas culturas de soja, milho, algodão e canola. No ano de 2011, a maior utilização de cultivos transgênicos ocorreu nos Estados Unidos, com uma área em torno de 69 milhões de hectares. O Brasil ocupou o segundo lugar com uma área de 30,8 milhões de hectares, sendo que deste total, foram cultivados 18,1 milhões de hectares com soja resistente ao glifosato (ISAAA, 2012). O expressivo e rápido aumento do cultivo de culturas transgênicas resistente ao glifosato é devido, principalmente, ao fato de que esta tecnologia simplifica o processo de controle de plantas daninhas e apresenta baixo custo em relação às demais opções de controle (VALDES; ASH, 2004).

O principal cultivo de transgênicos se refere a soja resistente ao herbicida glifosato (ISAAA,
2012). Este produto pertence ao grupo químico das glicinas substituídas, sendo um herbicida nãoseletivo e sistêmico, utilizado no manejo présemeadura em sistemas de plantio direto, em pósemergência em culturas resistentes, no manejo da vegetação de cultivos perenes, e na eliminação de plantas daninhas em ambientes aquáticos (RODRIGUES; ALMEIDA, 2005). Dentre os produtos fitossanitários, o glifosato é considerado um produto biologicamente seguro devido a baixa toxicidade e rápida degradação (CERDEIRA; DUKE, 2006). No entanto, a grande utilização de glifosato como método principal de controle tem resultado na evolução de plantas daninhas resistentes a este herbicida no Brasil e em vários outros locais do mundo (SHANER et al., 2012). Ainda, a utilização de glifosato tem sido relacionada com a imobilização de nutrientes no solo e nas plantas (BERNARDS et al., 2005) e com o surgimento de doenças em plantas expostas sistematicamente a este herbicida (JOHAL; HUBER, 2009; BÖHM; ROMBALDI, 2010). A molécula do glifosato é composta pelos grupos funcionais carbonila, amina e fosfonato que resultam em diferentes cargas iônicas em função do $\mathrm{pH}$ do meio (COUTINHO; MAZO, 2005). Em condições de $\mathrm{pH}$ fisiológico, as cargas resultantes dos processos de dissociação são monoânion e diânion. Estas cargas conferem ao glifosato forte 
característica quelante de metais sob diferentes dissociações ácidas (COUTINHO; MAZO, 2005).

A característica quelante do glifosato pode ocasionar a imobilização de nutrientes no solo e nas plantas (EKER et al., 2006). Este problema começou a ser identificado em áreas agrícolas no Brasil e nos Estados Unidos através de observações a campo de que a frequente aplicação de glifosato induziu a deficiência de $\mathrm{Fe}, \mathrm{Zn}$ e $\mathrm{Mn}$ em plantas resistentes a este herbicida (HUBER; MCCAYBUYS, 1993; HUBER, 2006). Esta deficiência pode decorrer dos processos relacionados à aplicação direta do glifosato sobre a planta ou da interação deste composto com o solo diminuindo a disponibilidade dos micronutrientes (EKER et al., 2006).

Em soja resistente ao glifosato pode ocorrer o amarelecimento das folhas após a aplicação deste herbicida originando o sintoma denominado de "yellow flashing"(ZOBIOLE et al., 2010). Este amarelecimento é consequência da imobilização de $\mathrm{Fe}$ e Mn pelo glifosato, e possivelmente, a duração do amarelecimento é dependente da habilidade das plantas de repor os níveis adequados destes elementos através da absorção radicular ou foliar (JOLLEY et al., 2004; Eker, 2006). No entanto, a ocorrência desta sintomatologia é variável em função da cultivar de soja, da dose e da formulação de glifosato, e de fatores ambientais (ZOBIOLE et al., 2010). Ainda, a significância desta sintomatologia para o metabolismo da planta e suas consequências para o rendimento de grãos da cultura são descritos apenas em poucos estudos, e ainda não permitem o completo conhecimento destes processos. Neste sentido, a análise da variação de parâmetros fisiológicos como a fluorescência da clorofila em interação com a disponibilidade de micronutrientes pode proporcionar o melhor diagnóstico dos fatores relacionados aos efeitos do glifosato em soja resistente a este herbicida.

O herbicida glifosato pode provocar alterações do fluxo de carbono assimilado pela fotossíntese e resultar em alteração dos parâmetros de fluorescência das plantas. As bases científicas dos efeitos de inibidores não fotossintéticos, como glifosato, na emissão de fluorescência não foram ainda identificadas. No entanto, é provável que a inibição das reações metabólicas não envolvidas na fotossíntese pode influenciar a taxa de síntese de metabólicos intermediários chave no metabolismo fotossintético e, consequentemente, interferir na taxa de fotossíntese e características de emissão de fluorescência (BARBAGALLO et al., 2003).
A imobilização de micronutrientes também pode afetar a síntese e proteção de clorofila e resultar em alteração dos parâmetros de fluorescência. Os parâmetros de fluorescência têm sido relacionados com a eficiência fotossintética (MAXWELL; JOHNSON, 2000; BALDASSARRE et al., 2011) e diretamente com a assimilação de $\mathrm{CO}_{2}$ (BAKER; ROSENQVIST, 2004). No entanto, também há evidências de que os inibidores de muitos processos metabólicos que não estão diretamente envolvidos no metabolismo fotossintético podem ocasionar modificações na cinética de fluorescência (BARBAGALLO et al., 2003). Neste sentido, o objetivo deste estudo foi identificar os efeitos do herbicida glifosato em interação com adubo foliar em cultivares de soja transgênica que apresentam a ocorrência de sintomatologia de fitointoxicação deste herbicida através de avaliações fisiológicas, nutricionais e do rendimento de grãos.

\section{MATERIAL E MÉTODOS}

Inicialmente foi realizado um experimento preliminar para identificar cultivares de soja que apresentaram a sintomatologia de amarelecimento foliar após a aplicação do herbicida glifosato. Esse experimento foi conduzido em casa-de-vegetação em delineamento completamente casualizado com quatro repetições. As cultivares de soja resistentes ao herbicida glifosato avaliadas foram Fundacep 59RR, Fepagro 36RR, CD 206RR, BRS 255RR, BRS TertúliaRR, BRS TauraRR e BRS EstânciaRR. Foram semeadas quatro sementes por vaso com posterior desbaste e manutenção de duas plantas por vaso. Os vasos possuíam capacidade de $1 \mathrm{~L}$, que foram preenchidos com solo do tipo Argissolo Vermelho Distrófico típico (STRECK et al., 2008). $\mathrm{O}$ herbicida glifosato (Roundup Original, $360 \mathrm{~g} \mathrm{~L}^{-1}$ e. a., CS, Monsanto do Brasil LTDA.) foi aplicado na dose de $900 \mathrm{~g} \mathrm{ha}^{-1}$ e. a. através do pulverizador costal pressurizado com $\mathrm{CO}_{2}$ munido de bicos DG 110.02, mantido à pressão constante de $200 \mathrm{kPa}$ e calibrado para vazão de $200 \mathrm{~L} \mathrm{ha}^{-1}$. A avaliação constou da injúria visual aos 5, 10 e 15 dias após a aplicação do herbicida. A maior sintomatologia de amarelecimento após a aplicação do herbicida glifosato foi constatada nas cultivares Fundacep 59 RR e CD 206RR (dados não apresentados).

O experimento a campo foi realizado na Estação Experimental Agronômica da Universidade Federal do Rio Grande do Sul (EEA/UFRGS), localizada no município de Eldorado do Sul, RS.O delineamento experimental foi de parcelas sub-subdivididas com três repetições. Na parcela principal, 
foi alocado o fator cultivar, na sub-parcela o fator doses do herbicida glifosato, e na sub-sub-parcela a adubação foliar. As cultivares utilizadas no experimento foram CD 206RR e Fundacep 59 RR que foram selecionadas com base no experimento preliminar descrito anteriormente. $\mathrm{O}$ tratamento herbicida constou da presença ou ausência de glifosato (Roundup Original, $360 \mathrm{~g} \mathrm{~L}^{-1}$ e.a., CS, Monsanto do Brasil LTDA.) aplicado na dose de 0, 900 e $1440 \mathrm{~g} \mathrm{ha}^{-1}$ e. a. O tratamento relacionado a adubação foliar constou da presença ou ausência do produto comercial TORPED (Oxiquímica) na dose de $1,5 \mathrm{~L} \mathrm{ha}^{-1}$. Este produto é um fertilizante foliar organomineral de classe A, utilizado para aplicações foliares. $\mathrm{O}$ produto contém a seguinte composição: Nitrogênio (N): 5,0\%; Fósforo (P2O5): 8,0\%; Potássio $\left(\mathrm{K}_{2} \mathrm{O}\right): 8,0 \%$; Cálcio $(\mathrm{Ca}): 1,0 \%$; Magnésio $(\mathrm{Mg}): 0,5 \%$; Enxofre (S): 2,5\%; Zinco (Zn): 1,0\%; Boro (B): 0,5\%; Manganês (Mn): 0,5\%; Cobre $(\mathrm{Cu})$ : 0,2\%; Ferro (Fe): 0,1\%; Molibdênio: $0,1 \%$; Carbono Orgânico Total: 6,0\%; Condutividade Elétrica (CE): 5,84 mS/cm; Índice Salino (IS): 75,5; Densidade à $20^{\circ} \mathrm{C}$ : $1,42 \mathrm{~g} / \mathrm{mL}$; Natureza Física: Suspensão Heterogênea, sendo que Zinco, Cobre, Manganês e Ferro complexados por $7 \%$ de aminoácidos. A aplicação dos tratamentos herbicida e adubo foliar foi realizada separadamente no estádio V3 (FEHR \& CAVINESS, 1977) através do pulverizador costal pressurizado conforme descrito anteriormente. Nas parcelas que não receberam glifosato, as plantas daninhas foram eliminadas através de arranquio manual. A análise de solo da área experimental foi realizada pelo procedimentos descritos no Manual de adubação e calagem para os estados do RS e SC (2004).

As unidades experimentais corresponderam a parcelas com oito linhas de soja com comprimento de $5 \mathrm{~m}$ e espaçamento entre linhas de $0,45 \mathrm{~m}$. A adubação antes da semeadura foi realizada com 300 $\mathrm{kg} \mathrm{ha}^{-1}$ de adubo químico NPK da fórmula 5-20-20. As sementes foram tratadas com inseticida fipronil e inoculadas com Bradyrhizobium japonicum estirpes SEMIA 5079 e 5080 nas doses recomendadas pelo fabricante. A semeadura foi realizada no dia 5 de janeiro de 2011 objetivando-se uma população de 350.000 plantas. $\mathrm{ha}^{-1}$. O controle de insetos-praga foi realizado com os inseticidas Bacillus thuringiensis, var. Kurstaki linhagem HD-I, lambdacialotrina e metamidofós, e o controle de doenças com o fungicida piraclostrobina e epoxiconazolona nas doses recomendadas pelos fabricantes.

As avaliações realizadas foram fluorescência da clorofila, teores foliares de $\mathrm{Fe}$ e $\mathrm{Mn}$, peso de 100 grãos, número de grãos por legume e rendimento de grãos. A fluorescência da clorofila foi avaliada através de leituras realizadas no folíolo central do terceiro trifólio, considerando-se a contagem de baixo para cima, em três plantas de cada repetição realizadas com o aparelho OS1-FL Chlorophyll Fluorometer (Opti-sciences). As leituras foram realizadas antes da aplicação do herbicida, 24 e 96 horas após a aplicação do herbicida. Os parâmetros da fluorescência da clorofila analisados foram fluorescência basal (Fs), máxima (Fms) e variável (Fvs), taxa de transporte de elétrons (ETR) e eficiência quântica (Yield). A avaliação do teor de $\mathrm{Fe}$ e $\mathrm{Mn}$ foliar foi realizada através da coleta de 20 trifólios de cada parcela antes, 24 e 96 horas após a aplicação dos tratamentos. As análises foram realizadas pelo método de digestão úmida nítrico-perclórica/ICPOES/ $2 \mathrm{mg} \mathrm{kg}^{-1}$. O peso de 100 grãos e número de grãos por legume foram estimados em amostra de três plantas por parcela. O rendimento de grãos foi corrigido para $12 \%$ de umidade, a qual foi determinada pela secagem dos grãos em estufa. Os dados foram submetidos à análise de variância pelo teste $\mathrm{F}$, com complementação através do teste de Tukey ao nível de 5\% de significância (SAS versão 8.0).

\section{RESULTADOS E DISCUSSÃO}

A quantificação da fluorescência da clorofila em plantas é uma ferramenta utilizada para avaliar o estado de estresse de uma planta através da análise do estado do sistema de transporte de energia do complexo fotossintético (STRASSER et al., 1995; LAZÁR, 1999). Moléculas de clorofila absorvem a energia da luz, que pode ser usada para a atividade fotossintética da folha, ser dissipada na forma de calor ou ser reemitida como fluorescência. Estes três destinos possíveis da energia fornecida pela luz competem entre si e o aumento de um é realizado em função da diminuição dos outros (MAXWELL; JOHNSON, 2000). Tanto a fluorescência variável (Fvs) quanto a fluorescência máxima (Fms) tem efeito direto na eficiência quântica (Yield), pois este parâmetro é a razão Fvs/Fms. No presente estudo as doses de glifosato de 900 e $1440 \mathrm{~g} \mathrm{ha}^{-1}$ e a utilização de adubação foliar não alteraram a eficiência quântica nas diferentes avaliações realizadas (Tabela 1). Em estudo realizado com a utilização de aminoácidos, isolado ou combinado com glifosato na dose de $1800 \mathrm{~g} \mathrm{ha}^{-1}$ na cultivar de soja BRS $242 \mathrm{RR}$, não ocorreram diferenças na eficiência quântica nos diferentes tratamentos em relação a sua linha isogênica Embrapa $58 \mathrm{CV}$ (ZOBIOLE et al., 2011b). Dentre os parâmetros de fluorescência da 
clorofila, a eficiência quântica tem se mostrado diferencial em relação aos efeitos do glifosato em soja transgência (ZOBIOLE et al., 2011a, 2011b).

Tabela 1. Eficiência quântica (Yield) em duas cultivares transgênicas de soja em função da aplicação de adubo foliar e de diferentes doses de glifosato avaliadas antes e após a aplicação do herbicida glifosato

\begin{tabular}{|c|c|c|c|c|c|c|c|}
\hline \multirow{4}{*}{ Cultivar } & \multirow{4}{*}{$\begin{array}{c}\text { Glifosa } \\
\text { to } \\
\mathrm{g} \mathrm{ha}^{-1} \\
\text { e. a. }\end{array}$} & \multicolumn{6}{|c|}{ Eficiência quântica } \\
\hline & & \multirow{2}{*}{\multicolumn{2}{|c|}{$\frac{\text { Antes da aplicação }}{\text { Adubo foliar }}$}} & \multirow{2}{*}{\multicolumn{2}{|c|}{$\begin{array}{c}24 \text { horas após aplicação } \\
\text { Adubo foliar }\end{array}$}} & \multirow{2}{*}{\multicolumn{2}{|c|}{$\frac{96 \text { horas após aplicação }}{\text { Adubo foliar }}$}} \\
\hline & & & & & & & \\
\hline & & Sem & Com & Sem & Com & Sem & Com \\
\hline CD 206RR & 0 & $0,576^{\mathrm{ns}}$ & $0,619^{\mathrm{ns}}$ & $0,533^{\mathrm{ns}}$ & $0,616^{\mathrm{ns}}$ & $0.533^{\mathrm{ns}}$ & $0.629^{\mathrm{ns}}$ \\
\hline CD 206RR & 900 & 0,588 & 0,599 & 0,548 & 0,524 & 0.674 & 0.55 \\
\hline CD 206RR & 1440 & 0,585 & 0,621 & 0,476 & 0,520 & 0.647 & 0.65 \\
\hline Fundacep 59RR & 0 & $0,626^{\mathrm{ns}}$ & $0,637^{\mathrm{ns}}$ & $0,555^{\mathrm{ns}}$ & $0,500^{\mathrm{ns}}$ & $0.649^{\mathrm{ns}}$ & $0.677^{\mathrm{ns}}$ \\
\hline Fundacep 59RR & 900 & 0,583 & 0,606 & 0,585 & 0,536 & 0.627 & 0.637 \\
\hline Fundacep 59RR & 1440 & 0,579 & 0,593 & 0,515 & 0,562 & 0.680 & 0.657 \\
\hline CV \% & & \multicolumn{2}{|c|}{6,67} & \multicolumn{2}{|c|}{9,45} & \multicolumn{2}{|c|}{12,19} \\
\hline
\end{tabular}

Outro parâmetro importante da fluorescência da clorofila é a taxa de transporte de elétrons (ETR). A ETR é uma medida em tempo real da atividade fotoquímica dos fotossistemas, porém, esta é mais sensível às variações das condições ambientais em comparação com a eficiência quântica (PIMENTEL et al., 2011). O fluxo de elétrons do fotossistema II indica, de modo geral, a taxa de fotossíntese e a ocorrência de danos ao fotossistema II, e se constitui como a primeira manifestação de estresse na folha da planta (MAXWELL; JOHNSON, 2000). No presente estudo, a utilização de adubo foliar e a aplicação de glifosato, na comparação dentro de cada dose do herbicida, tanto a dose de 900 como $1440 \mathrm{~g} \mathrm{ha}^{-1}$ reduziram a ETR nas plantas que não receberam o adubo foliar quando avaliado 24 horas após a aplicação dos tratamentos (Tabela 2). Já quando realizada a avaliação 96 horas após a aplicação dos tratamentos este efeito não foi observado (Tabela 2). $\mathrm{Na}$ avaliação realizada 24 horas após a aplicação dos tratamentos, a cultivar CD 206RR apresentou menor ETR nas doses de 900 e $1440 \mathrm{~g} \mathrm{ha}^{-1} \mathrm{de}$ glifosato nas plantas sem a aplicação de adubo foliar (Tabela 2).
Nas plantas que receberam adubo foliar, a dose de $1440 \mathrm{~g} \mathrm{ha}^{-1}$ de glifosato resultou maior ETR em relação a dose $900 \mathrm{~g} \mathrm{ha}^{-1}$ de glifosato ou com a testemunha sem aplicação do herbicida (Tabela 2). Este efeito pode ocorrer em virtude do estímulo relacionado a maior necessidade de metabolização de herbicida, o qual pode resultar em aumento de diversos parâmetros fisiológicos da planta. Considerando o efeito do adubo foliar dentro de cada dose do herbicida, a cultivar CD 206RR apresentou maior ETR nas plantas com aplicação do adubo foliar nos tratamentos com glifosato nas doses de 900 e $1440 \mathrm{~g} \mathrm{ha}^{-1}$ em relação a testemunha que não recebeu este tratamento (Tabela 2). Para a cultivar Fundacep 59 RR, a aplicação do herbicida reduziu a ETR nas plantas com e sem a aplicação de adubo foliar na avaliação realizada 24 horas após a aplicação dos tratamentos (Tabela 2). Na avaliação realizada 96 horas após a aplicação dos tratamentos, em ambas as cultivares, a dose de $900 \mathrm{~g} \mathrm{ha}^{-1}$ do herbicida aumentou a ETR considerando tanto o efeito de dose do herbicida como também do adubo foliar (Tabela 2). 
Tabela 2. Taxa de transporte de elétrons (ETR) ( $\mu$ mols elétrons $\left.\mathrm{m}^{-2} \mathrm{~s}^{-1}\right)$ em duas cultivares transgênicas de soja em função da aplicação de adubo foliar e de diferentes doses de glifosato avaliadas antes e após a aplicação do herbicida glifosato

\begin{tabular}{|c|c|c|c|c|c|c|c|}
\hline \multirow{4}{*}{ Cultivar } & \multirow{4}{*}{$\begin{array}{l}\text { Glifosato } \\
\mathrm{g} \mathrm{ha}^{-1} \\
\text { e. a. }\end{array}$} & \multicolumn{6}{|c|}{ Taxa de transporte de elétrons (ETR) } \\
\hline & & \multirow{2}{*}{\multicolumn{2}{|c|}{$\begin{array}{c}\text { Antes da aplicação } \\
\text { Adubo foliar }\end{array}$}} & \multicolumn{2}{|c|}{24 horas após aplicação } & \multicolumn{2}{|c|}{96 horas após aplicação } \\
\hline & & & & \multirow{2}{*}{$\begin{array}{c}\begin{array}{c}\text { Adubo } \\
\text { foliar }\end{array} \\
\text { Sem }\end{array}$} & \multirow{2}{*}{$\begin{array}{c}\begin{array}{c}\text { Adubo } \\
\text { foliar }\end{array} \\
\text { Com }\end{array}$} & \multirow{2}{*}{$\begin{array}{c}\begin{array}{c}\text { Adubo } \\
\text { foliar }\end{array} \\
\text { Sem }\end{array}$} & \multirow{2}{*}{$\begin{array}{c}\begin{array}{c}\text { Adubo } \\
\text { foliar }\end{array} \\
\text { Com }\end{array}$} \\
\hline & & Sem & Com & & & & \\
\hline CD 206RR & 0 & $40,43^{\text {ns1 }}$ & C 36,73 & A 265,9 a & B $123,03 \mathrm{~b}$ & $43.47^{\text {ns }}$ & B 42.97 \\
\hline CD 206RR & 900 & $39,36 \mathrm{~b}$ & A 111,76 a & B 46,86 b & B 125,36 a & $43.47 \mathrm{~b}$ & A $111.30 \mathrm{a}$ \\
\hline CD 206RR & 1440 & $40,46 \mathrm{~b}$ & B 58,93 a & B $43,93 \mathrm{~b}$ & A 163,00 a & $45.33^{\mathrm{ns}}$ & B 42.07 \\
\hline Fundacep 59RR & 0 & A 147,23 a & $38,96 \mathrm{~b}$ & A 248,70 & A 246,13 & $41.53^{\mathrm{ns}}$ & B 53.97 \\
\hline Fundacep 59RR & 900 & B 38,23 & $36,90^{\mathrm{ns}}$ & B 150,43 & B 200,36 a & $41.63 \mathrm{~b}$ & A $101.03 \mathrm{a}$ \\
\hline Fundacep 59RR & 1440 & A $145,06 \mathrm{a}$ & $41,70 \mathrm{~b}$ & B 145,63 & B 219,40 a & $52.40^{\mathrm{ns}}$ & B 41.40 \\
\hline $\mathrm{CV} \%$ & & & & & 15 & & 07 \\
\hline
\end{tabular}

${ }^{1}$ Médias seguidas de letra maiúscula diferente na coluna dentro de cada genótipo diferem estatisticamente no efeito de herbicida. Letras minúsculas diferem estatisticamente na linha em relação ao efeito de adubo foliar dentro de cada dose do herbicida na linha pelo teste de Tukey a 5\% de probabilidade.ns - não significativo $(\mathrm{p}<0,05)$.

Os efeitos do herbicida glifosato na ETR em soja transgênica podem ser mais evidentes em avaliações realizadas por períodos mais longos após a aplicação do herbicida, pois o principal mecanismo de ação do glifosato é relacionado à inibição da síntese de aminoácidos aromáticos (SHANER et al., 2012). Desta forma, este herbicida não atua diretamente na inibição da fotossíntese o que faz com que os danos deste herbicida possam não ser verificados nas avaliações iniciais. As pequenas oscilações da taxa de transporte de elétrons ocorridas ao longo do período avaliado podem estar relacionadas às condições do ambiente, visto que a capacidade fotossintética das plantas pode ser alterada por estresses bióticos ou abióticos como temperatura, radiação, deficiência hídrica, salinidade, presença de insetos ou fungos, entre outros (BOWNET et al., 2002; OLIVEIRA et al., 2002). No entanto, os efeitos secundários relacionados à imobilização de nutrientes causada pelo herbicida glifosato possuem maior importância de ocorrência logo após a aplicação e isto está relacionado ao fato do período de avaliação destes efeitos no presente estudo ter sido concentrados nas primeiras 96 horas após a aplicação.

No presente estudo, não foram observadas diferenças entre os efeitos dos tratamentos realizados sobre a fluorescência da clorofila em relação ao parâmetro relacionado a fluorescência basal (Fs) (dados não apresentados). Já em relação a fluorescência máxima (Fms) e fluorescência variável (Fvs) apresentaram diferenças somente na avaliação realizada 96 horas após a aplicação dos tratamentos onde a cultivar Fundacep 59 RR resultou em maior fluorescência variável em relação a cultivar CD 206RR (dados não apresentados).

Os efeitos negativos do glifosato e o benefício da aplicação de adubo foliar na cultura da soja em relação à disponibilidade de Ferro e Manganês foliar não foram comprovados no presente estudo (Tabelas 3 e 4 ).

Os elevados coeficientes de variação podem estar relacionados a variabilidade da amostragem. A não ocorrência de efeito dos tratamentos nos teores de ferro e manganês podem estar relacionados com os níveis de disponibilidade no solo destes micronutrientes. Conforme análise de solo da área experimental, os níveis para ferro e manganês foram de $1,3 \mathrm{~g} / \mathrm{dm}^{3}$ e $16 \mathrm{mg} / \mathrm{dm}^{3}$ que são considerados baixos e altos, respectivamente, em relação aos níveis de referência (Manual de Adubação e Calagem para os Estados do RS e SC, 2004). 
Tabela 3. Teor foliar de ferro em duas cultivares transgênicas de soja em função da aplicação de glifosato e de adubo foliar avaliado antes e após a aplicação do herbicida glifosato

\begin{tabular}{|c|c|c|c|c|c|}
\hline \multirow{4}{*}{ Cultivares } & \multirow{4}{*}{$\begin{array}{l}\text { Glifosato } \\
\text { g ha }^{-1} \text { e. a. }\end{array}$} & \multicolumn{4}{|c|}{ Ferro $\left(\mathrm{mg} \mathrm{kg}^{-1}\right)$} \\
\hline & & \multirow{2}{*}{\multicolumn{2}{|c|}{$\frac{\text { Antes da aplicação de glifosato }}{\text { Adubo foliar }}$}} & \multirow{2}{*}{\multicolumn{2}{|c|}{$\frac{96 \text { horas após a aplicação de glifosato }}{\text { Adubo foliar }}$}} \\
\hline & & & & & \\
\hline & & Sem & Com & Sem & Com \\
\hline CD 206RR & 0 & $245,0^{\mathrm{ns}}$ & $182,4^{\mathrm{ns}}$ & $114.0^{\mathrm{ns}}$ & $133.0^{\mathrm{ns}}$ \\
\hline CD 206RR & 1440 & $143,0^{\mathrm{ns}}$ & $145,0^{\mathrm{ns}}$ & $126.0^{\mathrm{ns}}$ & $115.5^{\mathrm{ns}}$ \\
\hline Fundacep 59RR & 0 & $140,0^{\mathrm{ns}}$ & $133,0^{\mathrm{ns}}$ & $140.5^{\mathrm{ns}}$ & $100.0^{\mathrm{ns}}$ \\
\hline Fundacep 59RR & 1440 & $150,0^{\mathrm{ns}}$ & $145,5^{\mathrm{ns}}$ & $130.0^{\mathrm{ns}}$ & $116.5^{\mathrm{ns}}$ \\
\hline $\mathrm{CV} \%$ & & & & & \\
\hline
\end{tabular}

Tabela 4. Teor foliar de manganês em duas cultivares transgênicas de soja em função da aplicação de glifosato e de adubo foliar avaliado antes e após a aplicação do herbicida glifosato

\begin{tabular}{|c|c|c|c|c|c|}
\hline \multirow{4}{*}{ Cultivares } & \multirow{4}{*}{$\begin{array}{l}\text { Glifosato } \\
\mathrm{g} \mathrm{ha}^{-1} \text { e. a. }\end{array}$} & \multicolumn{4}{|c|}{ Manganês $\left(\mathrm{mg} \mathrm{kg}^{-1}\right)$} \\
\hline & & \multirow{2}{*}{\multicolumn{2}{|c|}{$\begin{array}{c}\text { Antes da aplicação de glifosato } \\
\text { Adubo foliar }\end{array}$}} & \multirow{2}{*}{\multicolumn{2}{|c|}{$\frac{96 \text { horas após a aplicação de glifosato }}{\text { Adubo foliar }}$}} \\
\hline & & & & & \\
\hline & & Sem & Com & Sem & Com \\
\hline CD 206RR & 0 & $78,0^{\mathrm{ns}}$ & $70,5^{\mathrm{ns}}$ & $74.0^{\mathrm{ns}}$ & $76.0^{\mathrm{ns}}$ \\
\hline CD 206RR & 1440 & $88,5^{\mathrm{ns}}$ & $78,0^{\mathrm{ns}}$ & $78.5^{\mathrm{ns}}$ & $103.0^{\mathrm{ns}}$ \\
\hline Fundacep 59RR & 0 & $80,0^{\mathrm{ns}}$ & $88,5^{\text {ns }}$ & $73.5^{\mathrm{ns}}$ & $80.0^{\mathrm{ns}}$ \\
\hline Fundacep 5 RR & 1440 & $68,5^{\mathrm{ns}}$ & $62,5^{\mathrm{ns}}$ & $100.5^{\mathrm{ns}}$ & $103.0^{\mathrm{ns}}$ \\
\hline $\mathrm{CV} \%$ & & & & & \\
\hline
\end{tabular}

${ }^{\text {ns }}$ Não significativo $(\mathrm{p}<0,05)$.

Considerando que a disponibilidade de ferro no solo é baixa, as diferenças entre os genótipos podem estar relacionadas com a capacidade de cada genótipo em acumular ferro em ferritina, que é uma proteína de armazenamento de ferro encontrada em plantas, animais e bactérias (ZHAO, 2010). Estas proteínas tem a capacidade de armazenar uma quantidade maior de ferro na planta sem que este seja tóxico, sendo então liberado para atender as necessidades metabólicas das células em situação de deficiência da planta (MEILIANG, 2012). Nesta situação, a interferência de glifosato como imobilizador de $\mathrm{Fe}$ pode apresentar menor importância devido ao fornecimento de Fe através do compexo formado pela ferritina.

O constante interesse na obtenção de altos rendimentos nos cultivos de soja torna imprescindível determinar os efeitos de fatores que afetam o crescimento e desenvolvimento da cultura em relação a sua consequência no rendimento de grãos. O rendimento de grãos da cultivar Fundacep 59 RR foi maior em relação a cultivar CD 206RR (Tabela 5), independente da utilização ou não de adubo foliar e em todas as doses de glifosato aplicadas (Tabelas 5). Já entre as doses do herbicida, a cultivar Fundacep 59 RR teve um menor rendimento de grãos quando aplicado glifosato em ambas as doses, porém, a cultivar CD 206RR não apresentou diferenças com a aplicação do herbicida (Tabela 5). Com o objetivo de minimizar os possíveis efeitos negativos do glifosato, tem se realizado em lavouras de produção de soja a adubação foliar com micronutrientes. No entanto, este benefício pode não ocorrer devido à variabilidade do efeito direto do herbicida glifosato, a sensibilidade diferencial entre cultivares, a disponibilidade de nutrientes no solo e a variação do efeito de recuperação da adubação foliar, conforme evidenciado no presente estudo. 
Tabela 5. Rendimento de grãos em duas cultivares de soja transgênica em função da aplicação de glifosato e de adubo foliar.

\begin{tabular}{|c|c|c|c|c|c|}
\hline \multirow{3}{*}{ Genótipos } & \multicolumn{5}{|c|}{ Rendimento de grãos $\left(\mathrm{kg} \mathrm{ha}^{-1}\right)$} \\
\hline & \multicolumn{2}{|c|}{ Adubo Foliar } & \multicolumn{3}{|c|}{ Glifosato $\mathrm{g} \mathrm{ha}^{-1}$ e. a. } \\
\hline & Sem & Com & 0 & 900 & 1440 \\
\hline CD 206RR & B 2785,00 a & B 2783.36 a & B 2811,11 a & B 2848,38 a & B 2693,06 a \\
\hline Fundacep 59RR & A $3441,75 \mathrm{a}$ & A 3206.62 b & A 3562,19 a & A $3244,21 \mathrm{~b}$ & A $3166,16 \mathrm{~b}$ \\
\hline $\mathrm{CV} \%$ & \multicolumn{2}{|c|}{13,28} & \multicolumn{3}{|c|}{14,72} \\
\hline
\end{tabular}

No presente estudo, o peso de 100 grãos e o número de grãos por legume não foram afetados pelo efeito dos tratamentos (Tabela 6). Em estudo realizado com aplicação de glifosato em diferentes estádios e doses foi observado que a aplicação deste herbicida diminuiu $0,4 \mathrm{~kg} \mathrm{ha}^{-1}$ do rendimento de grãos a cada grama de e.a. ha ${ }^{-1}$ (ALBRECHT et al., 2011). Neste trabalho, o principal efeito ocorreu nos componentes do rendimento peso do grão e número de legume por planta quando da aplicação do herbicida glifosato na dose de $2880 \mathrm{~g} \mathrm{ha}^{-1}$ e.a. O efeito do glifosato na redução da produtividade para a cultivar Fundacep 59 RR encontrado no presente estudo esta de acordo com o observado em estudos realizados em casa de vegetação (SANTOS et al., 2007b) e em condições de campo em solo classificado como Latossolo Vermelho Distrófico típico de textura arenosa (ALBRECHT et al., 2011). No entanto, o efeito do glifosato na redução do rendimento de grãos de soja possui grande variação entre genótipos em interação com as condições ambientais (ANDRADE; ROSOLEM, 2011). A variação no rendimento de grãos entre as cultivares foi constatada também em estudo a campo, utilizando a dose de $900 \mathrm{~g} \mathrm{ha}^{-1}$ de glifosato em oito cultivares transgênicas comparadas com as suas linhas isogênicas próximas, onde houve redução no rendimento de grãos das cultivares Fepagro 36RR, BRS EstânciaRR, BRS TauraRR e Fundacep 59RR, e não afetou o rendimento de grãos das cultivares, BRS 255 RR, BRS Tertúlia RR, Fepagro 37RR e CD 206RR (WAGNER et al., 2014).

Tabela 6. Peso de grão e número de graõs por legume em duas cultivares de soja transgênica em função da aplicação de glifosato e de adubo foliar.

\begin{tabular}{lccccc}
\hline \multirow{2}{*}{ Genótipos } & \multirow{2}{*}{$\begin{array}{c}\text { Glifosato } \\
\text { g ha }\end{array}$} & \multicolumn{2}{c}{ Peso 100 grãos $(\mathrm{g})$} & \multicolumn{2}{c}{$\mathrm{N}^{\circ}$ grãos/legume } \\
\cline { 3 - 6 } & & \multicolumn{2}{c}{ Adubo foliar } & \multicolumn{2}{c}{ Adubo foliar } \\
\cline { 3 - 5 } CD 206RR & 0 & $17,17^{\mathrm{ns}}$ & $17,07^{\mathrm{ns}}$ & $2,05^{\mathrm{ns}}$ & $2,60^{\mathrm{ns}}$ \\
CD 206RR & 900 & $16,25^{\mathrm{ns}}$ & $16,97^{\mathrm{ns}}$ & $1,88^{\mathrm{ns}}$ & $2,03^{\mathrm{ns}}$ \\
CD 206RR & 1440 & $16,86^{\mathrm{ns}}$ & $18,17^{\mathrm{ns}}$ & $1,78^{\mathrm{ns}}$ & $2,05^{\mathrm{ns}}$ \\
Fundacep 59RR & 0 & $15,26^{\mathrm{ns}}$ & $16,13^{\mathrm{ns}}$ & $1,86^{\mathrm{ns}}$ & $1,75^{\mathrm{ns}}$ \\
Fundacep 59RR & 900 & $15,92^{\mathrm{ns}}$ & $15,91^{\mathrm{ns}}$ & $2,31^{\mathrm{ns}}$ & $2,12^{\mathrm{ns}}$ \\
Fundacep 59RR & 1440 & $15,87^{\mathrm{ns}}$ & $15,71^{\mathrm{ns}}$ & $1,78^{\mathrm{ns}}$ & $2,09^{\mathrm{ns}}$ \\
\hline CV \% & \multicolumn{3}{c}{4,04} \\
\hline ns Não significativo $(\mathrm{p}<0,05)$.
\end{tabular}

\section{CONCLUSÕES}

As aplicações do herbicida glifosato em dose de até $1440 \mathrm{~g} \mathrm{ha}^{-1}$ e.a e de adubo foliar não alteraram o acúmulo dos micronutrientes $\mathrm{Fe}$ e $\mathrm{Mn}$ nas cultivares de soja CD 206RR e Fundacep 59RR.

A aplicação do adubo foliar não foi eficiente como forma de aumentar o rendimento de grãos de soja nestas cultivares.

A cultivar CD 206RR não foi afetada pela aplicação do glifosato, enquanto que a cultivar
Fundacep 59 RR teve redução no rendimento de grãos devido a aplicação deste herbicida.

\section{AGRADECIMENTO}

A CAPES pelo fornecimento de bolsa ao primeiro autor. A FAPERGS pelo financiamento parcial da pesquisa. A EMBRAPA, CCGL TECNOLOGIA (CCGL-TEC), COODETEC $\mathrm{e}$ FEPAGRO pelo fornecimento das sementes das cultivares. 


\begin{abstract}
The chelant characteristic of glyphosate may result in the immobilization of micronutrients such as $\mathrm{Fe}$ and $\mathrm{Mn}$ in transgenic soybean resistant to this herbicide. However, the intensity of this effect and the results of mitigation practices are not fully understood. The objective of the study was to identify the effects of the herbicide glyphosate in interaction with the foliar application of micronutrients in two cultivars of transgenic soybean that demonstrated the occurrence of injury of this herbicide named yellow flashig. A preliminary experiment identified the larger intensity of yellow flashing in the cultivars CD 206RR and Fundacep 59 RR among seven cultivars evaluated. A field experiment was carried out where the treatments were the soybean cultivars described above, glyphosate at rates of 0 , 900 and $1440 \mathrm{~g} \mathrm{ha}^{-1}$ e.a. and the presence or absence of the foliar fertilization of micronutrients at $1,5 \mathrm{~L} \mathrm{ha}^{-1}$. The herbicide glyphosate and the foliar application of micronutrients did not change the concentration of Fe and Mn and the chlorophyll fluorescence in the cultivars CD 206RR e Fundacep 59RR. The herbicide glyphosate decrease the grain yield of the cultivar Fundacep 59RR and did not affect the cultvar CD 206RR. The foliar fertilization of micronutrients did not increase the soybean grain yield in the evaluated cultivars.
\end{abstract}

KEYWORDS: Iron. Chlorophyll fluorescence. Manganese. Roundup Ready soybean. Yellow flashing.

\title{
REFERÊNCIAS
}

ALBRECHT, L. P. et al. Desempenho da soja roundup ready sob aplicação de glyphosate em diferentes estádios. Planta Daninha, Viçosa, v. 29, n. 3, p. 585-590, 2011.

ANDRADE, G. J. M.; ROSOLEM, C. A. Absorção de manganês em soja RR sob efeito do glifosato. Revista Brasileira de Ciência do Solo, Viçosa, v. 35, n. 3, p. 961-968, 2011.

BAKER, N. R.; ROSENQVIST, E. Applications of chlorophyll fluorescence can improve crop production strategies: an examination of future possibilities. Journal of Experimental Botany, Oxford, v. 55, n. 403, p. 1607-1621, 2004. http://dx.doi.org/10.1093/jxb/erh196

BALDASSARRE, V.; CABASSI, G.; FERRANTE, A. Use of chlorophyll $a$ fluorescence for evaluating the quality of leafy vegetables. Australian Journal of Crop Science, Collingwood, v. 5, n. 6, p. 735-741, 2011.

BARBAGALLO, R. P. et al. Rapid, noninvasive screening for perturbations of metabolism and plant growth using chlorophyll fluorescence imaging. Plant Physiology, Rockville, v. 132, p. 485-493, 2003.

http://dx.doi.org/10.1104/pp.102.018093

BERNARDS, M. L.; THELEN, K.; PENNER, D. Glyphosate efficacy is antagonized by manganese. Weed Technology, Lacombe, v. 19, n. 1, p. 27-34, 2005.

BÖHM, G. M. B.; ROMBALDI, C. V. Transformação genética e aplicação de glifosato na microbiota do solo, fixação biológica de nitrogênio, qualidade e segurança de grãos de soja geneticamente modificada. Ciência

Rural, Santa Maria, v. 40, n.1, p. 213-221, 2010. http://dx.doi.org/10.1590/S0103-84782010000100037

BOWN, A. W.; HALL, D. E.; MACGREGOR, K. B. Insect footsteps on leaves stimulate the accumulation of 4- aminobutyrate and can be visualized through increased chlorophyll fluorescence and superoxide production. Plant Physiology, Rockville, v. 129, n. 4, p. 1430-1434, 2002. http://dx.doi.org/10.1104/pp.006114

CERDEIRA, A. L.; DUKE, S. O. The current status and environmental impacts of glyphosate-resistant crops: A review. Journal Environmental Quality, Madison, v. 35, n. 5, p. 1633-1658, 2006.

http://dx.doi.org/10.2134/jeq2005.0378

COUTINHO, C. F. B.; MAZO L. H. Complexos metálicos com o herbicida glifosato: revisão. Química Nova, São Carlos, v. 28, n. 6, p. 1038-1045, 2005. 
EKER, S. et al. Foliar-applied glyphosate substantially reduced uptake and transport of iron and manganese in sunflower (Helianthus annuus L.) plants. Journal Agricultural and Food Chemistry, Washington, v. 54, n. 26, p. 10019-10025, 2006. http://dx.doi.org/10.1021/jf0625196

FEHR, W. R.; CAVINESS, C. E. Stage of soybeans development. Ames: Iowa State University, 1977. 12p. (Special Report, 80).

HUBER, D. M. Strategies to ameliorate glyphosate immobilization of manganese and its impact on the rhizosphere and disease. In: LORENZ, N.; DICK, R. (Ed.). Proceedings of the Glyphosate Potassium Symposium. Iowa: Ohio State University: AG Spectrum, 2006.

HUBER, D. M.; MCCAY-BUYS, T. S. A multiple component analysis of the take-all disease of cereals. Plant Disease, Saint Paul, v. 77, p. 437-447, 1993.

ISAAA. Report on global status of Biotech/GM crops. Disponível em:

$<$ http://www.isaaa.org/resources/publications/briefs/43/pptslides/default.asp>. Acesso em: 21 maio 2012.

JOHAL, G. S.; HUBER, D. M. Glyphosate effects on diseases of plants. European Journal of Agronomy, Amsterdam, v. 31, n. 3, p. 144-152, 2009. http://dx.doi.org/10.1016/j.eja.2009.04.004

JOLLEY, V. D.; HANSEN, N. C.; SHIFFLER, A. K. Nutritional and management related interactions with iron-deficiency stress response mechanisms. Soil Science Plant Nutrition, Tokyo, v. 50, n. 7, p. 973-981, 2004. http://dx.doi.org/10.1080/00380768.2004.10408563

LAZÁR, D. Chlorophyll-a fluorescence induction. Biochemistry Biophysica Acta, Amsterdam, v. 1412, n. 1, p. 1-28, 1999. http://dx.doi.org/10.1016/S0005-2728(99)00047-X

MANUAL DE ADUBAÇÃO E CALAGEM PARA OS ESTADOS DO RS E SC, 2004. Sociedade Brasilera de Ciência do Solo. Comissão de química e fertilidade do solo. 10 ed. Porto Alegre. 400 p.

MAXWELL, K.; JOHNSON, G. N. Chlorophyll fluorescence - a practical guide. Journal of Experimental Botany, Oxford, v. 51, n. 345, p. 659-668, 2000. http://dx.doi.org/10.1093/jexbot/51.345.659

MEILIANG, L. et al. Effect of tannic acido $\mathrm{n}$ properties of soybean (Glycine max) seed ferritin: a model for interaction between naturally-occurring components in foodstuffs. Food Chemistry, Reading, v. 133, n. 2, p. 410-415, 2012. http://dx.doi.org/10.1016/j.foodchem.2012.01.052

MONQUEIRO, P. A. Plantas transgênicas resistentes aos herbicidas: situação e perspectivas. Bragantia, Campinas, v. 64, n. 4, p. 517-531, 2005. http://dx.doi.org/10.1590/S0006-87052005000400002

OLIVEIRA, J. G.; ALVES, P. L. C. A.; MAGALHÃES, A. C. The effect of chilling on the photosynthethic activith in coffe (Coffea arabica L.) seedlings. The protective action of chloroplastid pigments. Brazilian Journal Plant Physiology, Londrina, v. 14, n. 2, p. 95-104, 2002.

PIMENTEL, C. et al. Características fotossintéticas de Phaseolus vulgaris L. Hoehnea, São Paulo, v. 38, n. 2, p. 273-279, 2011.

RODRIGUES, B. N.; ALMEIDA, F. S. Guia de herbicidas. 5. ed. Londrina: Grafmarke, 2005. 591 p. SANTOS, J. B. et al. Avaliação de formulações de glifosato sobre soja Roundup Ready. Planta Daninha, Viçosa, v. 25, n. 1, p. 165-171, 2007.

SHANER, D. L,; LINDENMEYER, R. B.; OSTLIE, M. H. What have the mechanisms of resistance to glyphosate taught us? Pest Management Science, v. 68, n. 1, p. 3-9, 2012. http://dx.doi.org/10.1002/ps.2261 
STRASSER, R. J.; SRIVASTAVA, A. G. Polyphasic chlorophyll $a$ fluorescence transient in plants and cyanobacteria. Photochemistry and Photobiology, Hoboken, v. 61, n. 1, p. 32-42, 1995.

http://dx.doi.org/10.1111/j.1751-1097.1995.tb09240.x

STRECK, E. V.; KÄMPF, N.; DALMOLIN, R. S. D. Solos do Rio Grande do Sul. Porto Alegre: EMATER/RS, 2008. 222 p.

VALDES, C.; ASH, M. Economic impacts of biotech soybeans in Brazil on agricultura markets. In: In: MOSCARDI, F. et al. (Ed.). World soybean research conference. Londrina: Embrapa Soja, 2004. p. 341. (Embrapa Soja. Documentos, 228).

WAGNER, J. F.; MEROTTO JR., A. Parâmetros fisiológicos e nutricionais de cultivares de soja resistentes ao glifosato em comparação com cultivares isogênicas próximas. Ciência Rural, Santa Maria, v. 44, n. 3, p. 393 399, 2014. http://dx.doi.org/10.1590/S0103-84782014000300002

ZHAO, G. Phytoferritin and its implications for human health and nutrition. Biochimica et Biophysica Acta, Amsterdam, v. 1800, n. 8, p. 815-823, 2010. http://dx.doi.org/10.1016/j.bbagen.2010.01.009

ZOBIOLE, L. H. S. et al. Glyphosate affects chlorophyll, nodulation and nutrient accumulation of "second generation' glyphosate-resistant soybean (Glycine max L.) Pesticide Biochemistry and Physiology, Amsterdam, v. 99, p. 53-60, 2011a. http://dx.doi.org/10.1016/j.pestbp.2010.10.005

ZOBIOLE, L. H. S. et al. Nutrient accumulation and photosynthesis in glyphosate resistant soybeans is reduced under glyphosate use. Journal Plant Nutrition, Philadelphia, v. 33, n. 12-14, p. 1860-1873, 2010. http://dx.doi.org/10.1080/01904167.2010.491890

ZOBIOLE, L. H. S. et al. Prevenção de injúrias causadas por glyphosate em soja RR por meio do uso de aminoácido. Planta Daninha, Viçosa, v. 29, n. 1, p. 195-205, 2011 b. 